\title{
Educação escolar indígena: uma reflexão a partir da experiência na Escola Estadual Indígena Adolfo Ramiro Levi, Terra indígena Serra da Moça, Boa Vista/ RR
}

\author{
Mávera Teixeira Santos ${ }^{1}$ \\ Maxim Repetto ${ }^{2}$
}

\section{RESUMO}

O presente artigo apresenta uma reflexão sobre o processo de implementação de escolas em comunidades indígenas, em Roraima, especificamente sobre a experiência da Escola Estadual Indígena Adolfo Ramiro Levi, na comunidade Serra da Moça. As metodologias utilizadas foram a observação participante e a revisão crítica de bibliografia que discute a escolarização indígena e os modelos educacionais impostos aos povos indígenas. No primeiro momento, realizamos um breve levantamento histórico, partindo de uma visão crítica, para pensar a realidade escolar comunitária. No segundo momento, buscamos um debate sobre o papel que a escola representa atualmente na comunidade, demonstrando os dilemas vivenciados a partir dos impactos da escolarização imposta na vida dos povos indígenas, a desvalorização dos conhecimentos e de sua vivência, principalmente, em se tratando de uma comunidade próxima à capital do estado de Roraima. Dessa forma, abrimos um debate amplo sobre a educação escolar indígena, buscando novos métodos que visam corrigir lacunas históricas e contribuindo para pensar novas práticas pedagógicas que integrem discursos e práticas, tanto em sala de aula, quanto na escola de um modo geral.

PALAVRAS-CHAVE: Contradições na educação escolar indígena. Povos Wapichana e Macuxi. Educação Intercultural.

\section{Educación escolar indígena: una reflexión de la experiencia en la Escuela Estatal Indígena Adolfo Ramiro Levi, tierra indígena Serra da Moça, Boa Vista / RR}

\section{RESUMEN}

Este artículo presenta una reflexión sobre el proceso de implementación de escuelas en comunidades indígenas en Roraima, específicamente sobre la experiencia de la Escuela Indígena Adolfo Ramiro Levi, en la comunidad de "Serra da Moça". Las metodologías utilizadas fueron: observación participante e revisión crítica de la bibliografía que analiza la escolarización indígena y los modelos educativos impuestos a los pueblos indígenas. En el primer momento buscamos comprender el proceso histórico, a partir de una visión crítica, para pensar la realidad de la escuela y de la comunidad, en el segundo momento traemos este debate para pensar la escuela indígena y su papel actual en la comunidad, mostrando los dilemas experimentados en ella, los impactos de la escolarización impuesta en la vida de los pueblos indígenas, la desvalorización de sus conocimientos y sus formas de vida, especialmente, en el caso de una comunidad cercana a la capital del estado de Roraima. De esta manera, abrimos un amplio debate sobre la educación escolar indígena, desafiando las prácticas

\footnotetext{
${ }^{1}$ Universidade Federal de Roraima (UFRR), Boa Vista, Roraima, Brasil. E-mail: mavera.bv15@ @otmail.com.

${ }^{2}$ Universidade Federal de Roraima (UFRR), Boa Vista, Roraima, Brasil. E-mail: maxim.repetto@ yahoo.com.br.
} 
pedagógicas, buscando nuevos métodos que corrijan las brechas históricas y contribuyendo a pensar nuevas prácticas pedagógicas que integren discursos, tanto en la sala de clases como en la escuela.

PALABRAS ClAVE: Contradicciones en la educación escolar indígena. Pueblos Wapichana y Macuxi. Educación intercultural.

\section{Introdução}

A Escola Estadual Indígena Adolfo Ramiro Levi fica localizada na comunidade Serra da Moça, na área rural do município de Boa Vista, a $50 \mathrm{~km}$ do centro urbano da capital de Roraima. Encontra-se na região, denominada pelo movimento indígena, de Murupú. A comunidade pertence à Terra Indígena Serra da Moça, demarcada em ilha, com 11.626.7912 hectares, em 23 de maio de 1985, homologada em 29 de outubro de 1991, conta com uma população total de 799 habitantes, distribuídos em 189 famílias, que pertencem às comunidades indígenas Serra da Moça, Serra do Truaru e Morcego (CIR, 2017). Estas, por sua vez, eram, originalmente, Wapichana, da família linguística Aruak, os quais ainda são maioria, mas convivem na atualidade com outros povos da família de línguas caribe, como Macuxi e Ingarikó.

A comunidade Serra da Moça tem o mesmo nome da Terra Indígena demarcada. A comunidade tem uma população de 279 pessoas (70 famílias) e sua organização política é composta pelos $1^{\circ}$ e $2^{\circ}$ tuxauas, capataz e vaqueiro, as decisões são coletivas e tomadas em reuniões comunitárias.

Devido à proximidade entre a comunidade e a cidade, existem muitas diferenças do modo de vida, em relação aos povos que mantem menos contato com a sociedade envolvente, sendo que a história da região é marcada por conflitos entre fazendeiros e indígenas.

Do ponto de vista histórico, a escola, e todo o processo de colonização dos povos da região, estão altamente interligados, principalmente na mudança dos modos de vida dos povos indígenas, uma vez que a construção da escola, na comunidade, data de 1939. Nesse sentido, a nossa reflexão vai de encontro a um debate de como a escola ajudou a transformar as realidades sociais; além de um debate sobre o esvaziamento da história dos povos indígenas e dos conhecimentos próprios, na escola indígena; assim como do currículo escolar que eliminou os conhecimentos das comunidades em detrimento dos conteúdos nacionais e "civilizatórios".

Vale destacar que foi buscando compreender o lugar do professor indígena, no contexto da educação escolar nas terras indígenas em Roraima, que estas linhas foram sendo traçadas em forma de reflexões sobre a experiência de uma professora indígena Macuxi que 
atuou como docente junto a estudantes e a um corpo docente indígena, nas turmas da Educação para Jovens e Adultos (EJA) e no Ensino Médio Regular, nas turmas de $2^{\circ}$ e $3^{\circ}$ ano, na disciplina de Antropologia (SANTOS, 2019).

Ainda sobre a reflexão, construímos em diálogo com a experiência de formação na graduação, iniciação científica e no mestrado, sob a orientação do professor não indígena, a qual colaborou para o desenvolvimento da pesquisa, bem como a produção deste artigo. Ou seja, é uma reflexão conjunta de orientanda e orientador, sob a ótica da colaboração participativa.

Como professora indígena que tinha estudado na escola indígena e, posteriormente, na cidade, com professores não indígenas que atuam na formação superior de professores indígenas, fomos descobrindo, aos poucos, os conflitos sociais e políticos em torno da escola e da história, assim como da vivência diária dos povos indígenas. Na sala de aula, nas reuniões da escola e da comunidade, no diálogo com professores e alunos, e na reflexão e estudo acadêmico, conseguimos aprofundar a compreensão sobre estes processos.

Fomos tomando consciência das dificuldades na Educação Intercultural, comunitária, específica e diferenciada (RCNEI, 1998), assim como da dificuldade em trabalhar os conhecimentos indígenas, na escola, da desvalorização da história indígena, da dificuldade do auto reconhecimento dos indígenas como tais, da compreensão dos conflitos em torno dos saberes e processos de socialização e formação escolar, dos conflitos sociais e territoriais, tal qual a violência e a discriminação que sofrem os povos indígenas.

É pertinente observar a educação escolar indígena como um processo histórico marcado por diversas práticas sociais, assim como por discursos contraditórios, ao mesmo tempo em que representa uma conquista histórica para o movimento indígena, em busca do reconhecimento dos seus direitos e, sobretudo, da efetivação dos mesmos.

Do ponto de vista histórico, para compreender a atual situação da educação escolar indígena, precisamos olhar com criticidade a implantação das escolas para indígenas, no Brasil, contrastando-as com a realidade da região. Dessa forma, o tópico seguinte discutirá a educação oferecida aos povos indígenas, bem como algumas questões relacionadas à inserção das escolas nas comunidades. 


\section{A implantação das escolas nas comunidades indígenas em Roraima}

Os estudos da educação escolar oferecida aos povos indígenas, no Brasil, mostram que seus principais objetivos foram a integração do índio à sociedade nacional, sem respeito às diferenças culturais e linguísticas, pautadas numa perspectiva "integracionista", como apontam as experiências históricas da educação escolar indígena no primeiro momento de sua implantação nas comunidades (BONIN, 2012; LUCIANO, 2011).

De acordo com Luciano (2011), a implantação das primeiras escolas nas comunidades indígenas no Brasil colonial é "contemporânea" ao momento presente da história nacional, e fazem parte da consolidação do que o autor chama de empreendimento colonial. Quando o autor diz que são contemporâneas, está indicando que a consolidação dos objetivos da educação da colônia ainda está vigente de forma mascarada nos dias atuais.

Para o autor, a dominação política dos povos indígenas, a invasão de suas terras, a destruição de suas riquezas, e a extinção de sua cultura tiveram início no século XVI e foi resultado de práticas que sempre souberam aliar métodos de controle político à atividade escolar civilizatória.

Para melhor compreender o processo histórico da educação escolar, pesquisadores do tema classificam-no por etapas, a exemplo disso, Ferreira (2001) apresentou uma visão da história da escolarização junto a povos indígenas em quatro fases, sendo a primeira de catequese e educação a serviço do aniquilamento cultural no Brasil colônia. Uma segunda fase que ia da integração dos índios à comunhão nacional, ou seja, do SPI (Serviço de Proteção aos Índios) à FUNAI (Fundação Nacional do Índio), e a atuação de missões religiosas no século XX, temporariamente entre 1910 e início dos anos 1970.

Uma terceira fase que retrataria, desde os anos de 1970, a formação de projetos alternativos de educação escolar indígena, marcada pela participação de organizações não governamentais e pelos debates e encontros para a construção de uma educação para os índios. Teria ocorrido, ainda, uma quarta fase que, em parte, foi paralela ao surgimento e atuação das ONGS, marcadas por diversas experiências de autoria indígena, pelo surgimento do movimento indígena e pelos encontros de professores indígenas, os quais surgem em meados dos anos de 1970 e se intensificam na década de 1980. Na mesma linha, Candau e Russo (2010) afirmam que foram identificadas quatro etapas, esse estudo vai desde a época colonial até a atualidade, com a promulgação da Constituição Federal de 1988.

Em outra perspectiva, Luciano (2011), ao contrário, não utiliza as etapas acima mencionadas para compreender o processo de escolarização imposto aos povos indígenas, 
pois para o autor, existiu um único modelo de implantação da educação para os povos indígenas, pelos colonizadores, o qual esteve vigente até a década de 1960, sendo que, em seguida, nos anos 1970, se inicia uma categoria de discussão sobre a "educação escolar indígena" em contraposição ao modelo anterior, ou seja, segundo este autor, a categoria de educação escolar indígena, como a compreendemos hoje, não é aplicável a todo o processo histórico de imposição escolar, por outro lado é uma proposta nova, que somente vai surgir nas últimas décadas do século XX, e só se consolidará com a Constituição de 1988.

Esta nova proposta foi pensada e discutida pelas lideranças e organizações indígenas, surgindo como uma proposta de educação escolar indígena intercultural, bilíngue e diferenciada, reivindicada pelos povos indígenas e para os povos indígenas, propiciada pela Constituição Federal de 1988. Isto é, deixa de ser uma educação oferecida aos povos indígenas, com claro caráter de imposição, e passa a ser pensada e discutida por diversos povos indígenas, visando à pluralidade e especificidade de cada povo.

No que diz respeito à educação escolar oferecida aos povos indígenas, em Roraima, as pesquisas de historiadores e antropólogos mostram a implantação das escolas como um processo de inserção forçada, dos povos indígenas, na sociedade nacional, em outras palavras, um processo de imposição cultural e de desmonte dos modos de vida e dos processos de socialização e educação próprios, como ocorreu em toda a América Latina.

A escolarização indígena foi iniciada, em Roraima, por missionários católicos na primeira década do século XX, sendo que o ensino era ministrado por irmãs beneditinas em visitas esporádicas às comunidades mais próximas de Boa Vista; ou as crianças eram retiradas das comunidades para o internato mantido pelos beneditinos, em Boa Vista, e depois no Surumu (FARAGE, 1997).

Conforme Farage (1997) analisa, o SPI atuava de forma intensiva na região do Rio Branco, território do povo Wapichana, a partir da sede da Fazenda Nacional São Marcos, onde os missionários atuavam na escolarização, recrutando crianças para os internatos mantidos por eles. Corroborando com o histórico da educação, Repetto (2008a) diz que, na primeira metade do século $\mathrm{XX}$, duas instituições foram responsáveis pela educação dos índios, em Roraima:

A Igreja Católica, sob os cuidados da ordem dos Beneditinos, mantinha uma missão
localizada na margem esquerda do rio Surumu, que inicialmente recolhia crianças
órfãs e que, posteriormente, se transformou em uma escola/internato no seio do
território Makuxi e Wapichana. Por outro lado, o Serviço de Proteção ao Índio (SPI)
criou, a partir de 1923, uma escola na Fazenda Nacional São Marcos, que
desenvolveu ações de alfabetização e de formação profissional nos cursos de seleiro,
ferreiro, carpinteiro e marceneiro para indígenas, com o objetivo de formar mão de 
obra para o trabalho nas fazendas. Desta forma, passou-se a ensinar ofícios para que os indígenas pudessem trabalhar como mão de obra adequada a necessidade dos dominadores (REPETTO, 2008a, p. 2).

Logo após a entrada da ação missionária, conforme aponta Repetto (2008a), entrou em cena o Serviço de Proteção aos Índios (SPI), a partir daí o Estado passou a ter uma atuação mais ativa no projeto educacional destinado à formação "profissional e nacionalista" dos povos indígenas.

Nesse contexto, a história da educação, na região, está fortemente ligada à história da Igreja Católica e suas missões. Assim, os internatos se iniciaram na década de 1920, com a chegada dos beneditinos, presença que se estendeu até 1947, quando estes abandonam o estado de Roraima. Em 1948, a Missão Consolata assumiu a coordenação da ação missionária no Estado (NASCIMENTO, 2014).

Neste âmbito, a Escola Estadual Índio Ajuricaba foi fundada em 1939, na comunidade Serra da Moça, hoje nomeada de Escola Estadual Indígena Adolfo Ramiro Levi, localizada próxima a Fazenda São Marcos. Esta última localizada a poucos quilômetros abaixo do rio Uraricoera, em sua margem oposta, onde hoje é a Terra Indígena São Marcos.

\section{O processo de escolarização da comunidade Serra da Moça}

O processo de escolarização, na comunidade, assemelha-se a muitos outros, quanto à reivindicação de uma escola para educar as crianças. De acordo com Voltolini (2011), o Sr. Adauto relata que a primeira escola funcionou sem o reconhecimento oficial da Secretaria de Educação do Estado de Roraima; e o primeiro a lecionar na escola foi o professor Rogaciano, seguido dos professores e professoras Maria Luiza, Adauto, Maria Socorro, Odília, Maria Lúcia, Tereza, Miraci, dentre outros.

No dia 4 de abril de 1946, o Governador Interino do Território Federal do Rio Branco, atual Estado de Roraima, usando das atribuições conferidas pelos incisos I, V e VII do Decreto-Lei $N^{\circ}$ 5.839, de 21 de setembro de 1943, assinou o Decreto $n^{\circ} 42$, criando a escola mista denominada Índio Ajuricaba (VOLTOLINI, 2011).

A escola localizada na Serra da Moça significou, na época, uma conquista para os povos da região, pois muitos dos pais e jovens daquele período da implantação relatam que procuravam melhor capacitação para os seus filhos, na própria comunidade, evitando assim, a saída para a cidade. Muitos de seus moradores trabalhavam nas fazendas próximas, mas 
recebiam pagamentos básicos e poucos recursos, por isso a escola comunitária veio a ser para os mais jovens, um motivo de mudança para melhorar de vida (VOLTOLINI, 2011).

No livro "Os Wapixanas da Serra da Moça: entre o uso e desuso das práticas cotidianas (1930/1990)", Maia (2014) debate sobre a educação dos povos indígenas na comunidade, trazendo dados interessantes e relatos da vivência diária que foi modificada com a chegada da escola. Ela diz:

[...] a partir da implantação da escola convencional, não é difícil constatar que se tornou um dos principais meios de descaracterização da cultura tradicional do grupo. [...] os conteúdos trabalhados não se adequam as experiências de vida dos alunos (MAIA, 2014, p. 35)

Para Maia (2014), a escola contribuiu para o processo de mudança, principalmente, entre a juventude da época, inserindo novos valores e novas formas de vida. É pertinente observar que a implantação das escolas, nas comunidades, vem com a mesma noção de mudanças no modo de viver.

Entre os Wapichana da região é nítida essa mudança, principalmente no que diz respeito à língua materna, hoje poucas pessoas da comunidade falam fluentemente a língua Wapichana, isto, em parte, é produto de uma política educacional que desvalorizou os conhecimentos indígenas. Os materiais didáticos, os planos de aula, os conteúdos de estudo, a própria estrutura curricular da escola não levavam em consideração os modos de vida da comunidade. O modelo e os valores apresentados na escola foram os da sociedade envolvente.

Os pais dos alunos e as senhoras mais idosas da comunidade relataram as punições que sofriam para não falarem a língua indígena, desde a palmatória a castigos no sol e de joelho. Todo esse processo acarretou mudanças no modo das relações entre a comunidade, a sociedade envolvente e o mundo, acarretando na desvalorização da própria vivência.

Cabe ressaltar que as comunidades Wapichana dessa região foram as primeiras a entrar em contato com a sociedade envolvente e sofreram uma desagregação nos seus hábitos e formas de vida. A escola, por sua vez, teve um papel estimulador nessa mudança, voltando a formação das crianças e dos jovens para atender as necessidades da sociedade nacional, ao mesmo tempo em que não permitia compreender as necessidades locais.

Esta situação vivida pelos povos indígenas fez com que estes se organizassem politicamente, através de organizações, suas lideranças se deslocavam até a capital federal em defesa de seus direitos e o contato com outras lideranças alimentou, entre si, o desejo de aprender a ler e a escrever, e de compreender melhor a situação vivida por eles. (D' ANGELIS, 2012). 
Se por um lado a educação escolar nas comunidades indígenas foi imposta como instrumento de controle do sistema nacional sobre os povos indígenas, no contexto mais amplo da "integração nacional", ela foi se transformando ao longo do tempo em necessidade e reivindicação, por meio da qual se busca, a partir da perspectiva indígena, moldar ferramentas de sobrevivência e de luta.

\begin{abstract}
Nas últimas décadas, a educação indígena buscou uma definição própria para si, levantando a bandeira de uma educação específica e diferenciada. Trata-se de uma luta para conquistar espaços jurídicos, políticos, pedagógicos e de gerenciamento desse processo educacional. Desse modo, é que as diferentes vozes e propostas de educação indígena procuram, desde perspectivas diversas, avançar nas definições concretas e particulares, visando consolidar as propostas reais de uma educação significativa para esses povos (REPETTO, 2008b, p.1).
\end{abstract}

Desde os anos de 1970, houve uma luta política pela reapropriação da escola, começando com o desejo de ensinar as línguas e os conhecimentos indígenas; depois com a substituição dos professores não indígenas por indígenas; com as reivindicações por uma educação específica e diferenciada, bandeira esta levantada pelas organizações indígenas de caráter territorial e notadamente pelas organizações de professores indígenas, como o Conselho dos Professores Indígenas de Amazonas, Roraima e Acre (COPIAR/1988) que, posteriormente, passou a se chamar Conselho de Professores Indígenas da Amazônia COPIAM/1990) (SILVA, 1999); ou Organização dos Professores Indígenas de Roraima (OPIR/1990) (REPETTO, 2006), abrangendo desde o corpo docente aos cargos de serviços gerais.

Nesse contexto, depois de muita luta e resistência, a comunidade Serra da Moça e as demais comunidades vizinhas modificaram o nome da Escola que se chamava Índio Ajuricaba para o nome de uma liderança simbólica que lutou pela demarcação da Terra Indígena, passando a se chamar Escola Estadual Indígena Adolfo Ramiro Levi, antiga liderança.

As transformações sociais que as escolas indígenas vivenciaram, frutos das lutas e conquistas do movimento indígena organizado, junto aos seus colaboradores, devem ser debatidas na perspectiva daquilo que Luciano (2011) discute como a diferença entre a escola indígena real e a escola indígena ideal. $\mathrm{O}$ autor debate os dilemas enfrentados pelas escolas desde as conquistas de direitos dos povos indígenas a partir da Constituição Federal de 1998. Neste sentido, cabe a nós elencar um debate sobre a escola indígena atual, focando na vivencia das comunidades e nas práticas educativas adotadas.

Conforme Bonin (2012) pontua, a Constituição Federal produziu uma virada conceitual que alterou as relações do Estado com os povos indígenas. Esta mudança de 
perspectiva exigiu que as leis específicas sobre a educação fossem reformuladas para torná-las compatíveis aos princípios mais gerais. Dessa forma, o direito indígena vem sendo regulamentado desde 1988, através de textos legais.

Do ponto de vista do conjunto das normas gerais é importante destacar o Plano Nacional de Educação, Lei $n^{\circ}$ 10. 172. Sua elaboração foi definida na própria Constituição Federal, no Artigo 214. Este plano tem como objetivo articular as ações do poder público em metas comuns, a fim de assegurar o desenvolvimento de processos de educação escolar em todos os níveis (BONIN, 2012).

Existem inúmeras normas que regulamentam a educação escolar indígena, porém, ainda que a conquista desses direitos seja fundamental, argumentamos que não foram suficientes para produzir um impacto relevante em sala aula, de maneira que as escolas pudessem mudar sua perspectiva anterior por completo. Em certo sentido, as escolas indígenas vivenciaram as contradições do próprio sistema educacional.

D`Angelis (2012) questiona a autonomia das escolas indígenas que, na prática, não usufruem desse benefício. Em nossa opinião, vemos mais abandono por parte do sistema escolar do que autonomia por parte de professores e direção das escolas, os quais estão submetidos às orientações curriculares, às 800 horas e aos 200 dias letivos. D'Angelis questiona também a própria participação dos professores indígenas, nesse processo, a qual nem sempre é autocrítica e questionadora, tal qual Gasché (2010) questiona aos professores indígenas que reproduzem discursos de interculturalidade, mas que na prática reproduzem os modelos escolares dominadores, o que não ajuda na consolidação dos debates em questão.

Em perspectiva crítica, apresentamos como continuação uma reflexão sobre experiências com alunos indígenas em sala de aula indígena.

\section{Experiências em sala de aula}

No imaginário intelectual de quem não estuda profundamente a educação escolar indígena pós conquista de direitos via Constituição Federal de 1988, os povos indígenas vivem uma educação intercultural, respeitando os direitos étnicos, culturais, estudando a história do próprio povo, respeitando os calendários próprios, os conhecimentos tradicionais etc.

Mas a realidade diverge deste tipo de pensamento, pois as escolas passam por diversas dificuldades que vão desde a falta de materiais didáticos básicos para o funcionamento das escolas, até o próprio funcionamento e a estrutura da escola que muitas vezes nem existe, sem 
falar nas dificuldades que são colocadas pelo modelo de ensino e de estrutura curricular das escolas indígenas.

Sanchotene e Neto (2006), no artigo sobre hábitos profissionais, em que debatem currículo oculto e cultura docente numa perspectiva crítica, nos chamam a atenção para desenvolver uma análise do sistema escolar de ensino, em que a instituição escola é responsável pela reprodução das relações sociais desiguais da sociedade, não descartando os conflitos e as possibilidades de resistência que coexistem nas instituições.

Percebemos que muitas das relações sociais de poder reproduzidas na escola indígena pertencem ao modelo anterior, colonizador, seja de uma forma explícita ou de uma forma mais sutil, aquilo que Silva (2003) caracteriza como a contaminação que as redes do poder fazem sobre as relações sociais, isto é, muitas vezes se pretende uma coisa, mas por forças ocultas e pela reprodução desses poderes, se reproduz o status quo.

$\mathrm{Na}$ sala de aula, por exemplo, alunos do $2^{\circ}$ e $3^{\circ}$ ano Médio Regular, na disciplina de Antropologia, nos espantaram quando sentimos a vergonha deles ao ser pedido que se apresentassem, dizendo seu povo, idade e comunidade. No ensino médio, estudam alunos das comunidades vizinhas. Eles falavam o nome, a idade, a comunidade, mas quando chegavam à identificação do povo ao qual pertenciam, era um pouco difícil para eles, eles reconheciam que o pai ou a mãe era indígena, mas eles mesmos não se sentiam indígenas, não se viam como pertencentes ao povo indígena, relacionavam o mundo indígena como sendo algo do passado das suas famílias, mas não do presente.

Já havíamos iniciado as aulas com a leitura de alguns textos relacionados aos estudos antropológicos, com a apresentação do conteúdo a ser trabalhado, em sala de aula, sendo que a aula era uma vez por semana e com duração de 45 minutos em cada turma. O plano de aula semanal estava elaborado, mas teríamos que entregar, para a gestão escolar, o plano anual.

Com o intuito de elaborar o plano de aula anual, que discutisse a história nacional, abordando questões da vivência dos povos indígenas no Brasil, fomos à biblioteca, pedimos sugestões da coordenação da escola e sem sucesso, ninguém tinha sequer noção de como abordar o tema que, pelo visto, não tinha sido tratado nos anos anteriores.

Perguntamo-nos: como uma escola indígena não aborda a história dos povos indígenas e se quer tem referência para a elaboração de um plano de aula sobre os povos indígenas? Em nosso imaginário, as escolas indígenas educavam e abordavam assuntos sobre os povos indígenas e a conquista de seus direitos.

Os discursos de professores indígenas, em assembleias, ou mesmo em reuniões do corpo docente das escolas, são de que está sendo realizado o ensino específico, diferenciado e 
intercultural, mas na prática pedagógica do dia a dia, como docente indígena e não indígena, percebemos a contradição nas falas.

Nas perguntas elaboradas para os alunos, no quadro, observamos o desconhecimento sobre a história da colonização, mas também sobre a história mais recente, da demarcação da terra, ou seja, uma compreensão e reflexão sobre a organização social da comunidade, pois não sabiam responder questões relacionadas à própria vivência, era como se estivéssemos perguntando algo longe de suas realidades.

Outro exemplo pode ser tirado da semana de comemoração da demarcação da Terra Indígena Serra da Moça. Nessa ocasião, a direção da escola solicitou aos professores que organizassem uma comemoração envolvendo estudantes e comunidade, o que seria contado como dia letivo.

Então, cada professor preparou um plano de aula conforme as suas respectivas disciplinas, a professora aqui presente, da área de humanas, conversou com um colega na cidade e o convidou para fazer pinturas corporais indígenas nos alunos que se interessassem, o que tinha sido combinado e aprovado pela coordenação da escola.

A pedido do artista, os alunos conseguiram jenipapo e carvão para fazer as misturas de tintura, preparando, assim, o material. Muitos alunos se interessaram, outros ficaram apenas curiosos, procuravam saber sobre o significado das pinturas e se iria demorar a sair do corpo. Alguns alunos fizeram as pinturas, outros não, de forma que ninguém foi obrigado.

Contudo, no dia seguinte, havia uma "conversa" na escola de que a arte no corpo dos alunos eram coisas demoníacas. Algumas das crianças que fizeram pinturas no corpo estavam apavoradas, outras tinham lavado tanto que o braço ficou dolorido. Foi necessário conversar com a professora das crianças e alguns pais, para acalmá-los e explicar-lhes que as pinturas nada tinham a ver com espíritos demoníacos.

Tendo em vista estas contradições, buscamos novas formas de trabalhar com alunos na sala de aula. Montamos um plano de estudo para o reconhecimento da história do povo Wapichana da região, bem como sobre as contribuições dos povos ao longo do processo histórico, tendo como objetivo que os alunos conseguissem refletir sobre a sua realidade, para que reconhecessem que todo conhecimento é uma produção social válida e que toda a experiência social produz conhecimento.

Arroyo (2011) argumenta que para superar visões distanciadas, segregadas das experiências, de conhecimentos e de coletivos humanos e profissionais é preciso reconhecer que há uma pluralidade e diversidade, e não uma hierarquia de experiências humanas e de coletivos. De acordo com o autor, essa diversidade de experiências é uma riqueza, porque 
produz uma rica diversidade de conhecimentos e de formas de pensar o real e de pensar-nos como humanos.

O livro "Propostas educativas em cidadania intercultural", organizado por Repetto et al. (2008), nos auxiliou na elaboração dos planos de aula com diferentes debates. Ao perceber a vergonha dos alunos, ao falarem do seu povo, procuramos trabalhar com eles a autoestima e a história do povo Wapichana, demonstrando que as mudanças no modo de pensar e de agir são frutos de um processo histórico violento e de resistência.

Inicialmente, através da leitura dirigida de textos selecionados, refletimos juntos sobre o que é cultura, identidade e cidadania, explicitando aos alunos como esses conceitos nos ajudam a repensar a visão que homogeneizou e individualizou os povos indígenas, demonstrando, através da reflexão, que os processos históricos foram construídos por pessoas, e que pelas mesmas podem ser transformados (REPETTO, 2008).

Na medida em que avançávamos na reflexão sobre cultura e as transformações vividas pelos povos indígenas, os alunos iam compreendendo que cultura é, sobretudo, visão de mundo, concepção da realidade, vivência, compreensão e construção da própria história, da natureza e do mundo, e sobre sua relação com eles.

Nesta perspectiva, a própria natureza é uma produção cultural, pois através da cultura ela se pensa e transmite. A linguagem é um sofisticado produto cultural, e nele cada povo encontra palavras próprias para expressar o mundo, de acordo a seu conhecimento e relação com ele (REPETTO, 2008, p.64).

O texto é de fácil interpretação, os alunos, a cada aula, repensavam as atitudes e relatavam que não tiveram acesso a um ensino que despertasse o interesse pelos conhecimentos ou histórias indígenas. No imaginário social dos alunos não eram mais índios, para eles indígenas estavam no passado, vestidos de tanga, andando sem roupa ou vivendo em ocas, como mostravam os livros escolares.

Estes eram os relatos dos alunos quando pedíamos para que comentassem o texto, em contraponto com o dia a dia deles na comunidade, pois vestem roupas e fazem coisas que consideram atuais, e não do passado. Fazer com que os alunos compreendessem o processo de “integração" dos povos indígenas, a sociedade nacional, foi importante para que se sentissem parte do processo histórico.

Um dos assuntos que mais chamou a atenção dos alunos foi a diversidade dos povos indígenas existentes no país, o outro foi o debate sobre preconceito e discriminação que sofrem os povos indígenas, assim como também o que eles próprios passavam em algumas situações. Quando discutimos isto, em sala, houve inúmeros relatos de quando vão à cidade 
ou quando visitam outras escolas. Tiveram relatos, também, de vivências na própria sala de aula, em relação aos colegas, puderam rever, então, os seus próprios posicionamentos, pois alguns alunos da escola são não indígenas de assentamentos de reforma agrária. A escola indígena, por ser próxima ao assentamento, os atende.

Não só os alunos puderam repensar as suas histórias e contexto social. Nós, também, enquanto professora indígena e orientador não indígena formador de professores indígenas, respectivamente, repensamos a prática escolar frente à realidade das comunidades e das escolas indígenas em Roraima. Paulo Freire (1996) nos ajudou quando se refere à reflexão sobre a prática social dos professores, o que possibilitou que olhássemos para nós mesmos enquanto seres históricos e sociais.

Do ponto de vista da reflexão, aprendemos também sobre a nossa prática no momento em que ensinamos, temos a capacidade de aprender, não só apenas para nos adaptar, mas, sobretudo, para transformar a realidade, para nela intervir recriando-a, na fala do autor: "aprender para nós é construir, reconstruir, contrastar para mudar [...]" (FREIRE, 1996, p. 28).

Para além da reflexão, a pesquisa nos colocou num posicionamento crítico frente a educação imposta pela sociedade não indígena, assumindo uma postura contra o ensino de caráter eurocêntrico e ocidental que ainda se faz presente, muitas vezes, em nossas atitudes, por vezes ainda nos discursos, deixando vazia a nossa prática social e pedagógica.

É necessário pensar os processos históricos da educação escolar indígena, os modelos de ensino nas escolas. Refletir sobre tudo isso exige pesquisa, debates, leitura e observação. Foi nesse contexto que sentimos as falhas no ensino voltado para a realidade dos alunos, o próprio estudo dos povos indígenas, sobre os quais pouco se estuda na escola indígena.

A desvalorização do ensino não só vem da sociedade nacional, mas também dos professores indígenas que não conseguem perceber que são heranças de um sistema educacional colonizador, que repetem o ensino que desvaloriza a cultura, que mascara a realidade com discursos disfarçados, relativizando a história indígena em sentido negacionista.

Gasché (2010) critica a relativização da história indígena quando os próprios indígenas dizem que não houve conflitos sociais, quando dizem que sempre houve boas trocas entre colonizadores e colonizados e que hoje em dia, nas comunidades mais próximas aos centros urbanos, há uma harmonia entre povos. Do ponto de vista do autor, a interculturalidade é cheia de conflitos, interculturalidade não é harmonia, muito pelo contrário. 
Neste sentido, concordamos com o autor quando olhamos para a realidade do ensino ou mesmo para a história da comunidade Serra da Moça e percebemos como os povos indígenas foram subjugados, escravizados pelas fazendas e silenciados deliberadamente em certos momentos da história. Conflitos são escondidos quando não se pode falar a própria língua por vergonha ou por se sentir diminuído. O inimigo se torna íntimo e passa morar dentro de nós. Internalizamos o dominador e nos vigiamos e nos punimos internamente.

Os conflitos com fazendeiros, na região, não são citados na escola, são motivos de segredo, em certo sentido é uma forma de proteção. Na escola, os textos que refletem questões de invasão de terra, de geografia, da comunidade, do ensino e estudo, assim como do uso das línguas indígenas, são tratados como secundários, menos importantes que outros assuntos que sim, são considerados importantes e se relacionam com a sociedade nacional dominante. Saber articular o conhecimento local com o global tem sido muitas vezes difícil, pois é um cabo de guerra desigual. No meio dessas contradições, ganham preferência os livros didáticos, desarticulando, assim, assuntos que valorizam a vida na comunidade.

A invisibilização é dolorosa. É muito clara a decisão consciente de muitas famílias Macuxi e Wapichana que, na geração dos pais ou avôs das atuais gerações, deixaram de ensinar as línguas indígenas aos seus filhos para evitar que sofressem preconceito, que apanhassem na escola e que fossem vistos como inferiores no contexto altamente discriminador e preconceituoso de Roraima.

Para Gasché (2010), muitas vezes a escola, nas comunidades indígenas, prepara os jovens para desenvolver e trabalhar o modo de vida urbano, não leva em conta o fato de o modo de vida indígena também requer competências e habilidades próprias. Não desenvolve, não promove e nem revaloriza a cultura indígena. Nesse sentido, é sintomático que, na escola, se estude a história do mundo, Grécia, Roma e o antigo Egito, mas não se conhece o enredo da chegada dos portugueses no rio Branco, não se conhece como foram promovidos os aldeamentos no século XVIII, como se impuseram à força as fazendas no século XX, ou como ainda na atualidade os perniciosos garimpos invadem as terras indígenas.

Também nos chama a atenção o fato de muitos indígenas falarem na valorização da cultura indígena, enquanto que nas práticas sociais da comunidade isso é desmentido, ou como Gasché (2010) questiona, entre educadores indígenas e não indígenas, se fala em educação intercultural, porém de forma vazia e sem conteúdo. O ponto mais crítico, segundo este autor, é quando os educadores indígenas falam da cultura indígena, cheios de palavras e de discursos de valorização, mas na prática desvalorizam as vivências do dia a dia, com a comunidade. Nas escolas indígenas, quando perguntamos sobre como entram os 
conhecimentos indígenas, na sala de aula, muitos olham para os mais velhos, ou então, apenas para o professor de língua indígena, ou, ainda, para as aulas práticas de projeto, ao mesmo tempo em que sentem dificuldade de pensar em como fazer entrar os conhecimentos indígenas no ensino da história, da matemática, das ciências, do português e de todas as outras disciplinas escolares.

Nesse sentido, como educadora indígena e educador não indígena, aqui, refletindo juntos, vemos como as práticas colonizadoras ainda permanecem vivas e como é importante trazer a luz debates sobre cidadania e povos indígenas, pois a história nos coloca diante de contradições, de conflitos e de questionamentos que podem vir de qualquer direção e que nos mostram como é frágil o reconhecimento que a sociedade faz do professor, e a difícil tarefa que todo dia temos diante de nós.

\section{Considerações finais}

A pesquisa e a experiência na escola indígena trouxeram perguntas e reflexões importantes para um campo amplo de debate sobre a educação escolar indígena no contexto roraimense. Acreditamos que, em certo sentido, o processo de colonização e escolarização demonizou e envergonhou os modos de vida dos povos indígenas, mas dentro deles existe também o potencial de diálogo e reflexão capaz de reverter preconceito, racismos ainda existentes e impregnados na sociedade. Existe o potencial de reconhecer a importância de um debate mais amplo sobre território e sobre os conflitos vividos pelos povos da região.

A experiência em sala de aula também foi enriquecedora, na medida em que esta pesquisa foi realizada em colaboração entre o professor orientador e a respectiva professora indígena, atuando em escola indígena. Em contraponto, a experiência do professor orientador não indígena se viu impactada e este se colocou a refletir sobre os desafios da formação de professores indígenas e sobre os conflitos que enfrentamos na sala de aula, na universidade que, por sua vez, não está isenta dos problemas pelos quais passamos na sala de aula, na comunidade. Percebemos, assim, que a educação escolar indígena é um processo contínuo de experiências, envolvendo um campo amplo de muitos debates.

Desenvolver um trabalho que enfrente e desfaça o racismo e o preconceito é uma tarefa de toda uma vida, longo, demorado e doloroso, o qual precisa recomeçar todos os dias, superando os discursos da valorização, para colocar em prática o respeito pela diversidade e pelas pessoas. 
Faz parte desta luta buscar estratégias para que a juventude indígena olhe a Terra como um campo de possibilidades, de trabalho, desenvolvimento social, cultural e econômico, para que parem de pensar que a única alternativa depois de concluir o ensino médio é sair da comunidade para a cidade e se submeter a uma relação de patrão/empregado. Ao contrário, que esta juventude indígena possa perceber novas possibilidades.

Precisamos olhar atentamente e com criticidade as nossas práticas pedagógicas, nossas práticas sociais e, principalmente, nosso posicionamento como professores não apenas em escolas indígenas, mas também na universidade.

Temos um campo de possibilidades. Não só nos opor a velhas práticas, mas por pensar cada vez mais em uma pesquisa diária, com responsabilidade social, saber articular e contrastar os conhecimentos, a história local e a global e tornar interessante o estudo baseado no do dia a dia dos alunos, assim como buscar compreender os macros processos.

Cabe a nós, professores indígenas e não indígenas, como já dito, buscar novos referenciais teóricos e metodológicos que nos deem subsídios, que nos apoiem, rompendo velhas práticas e nos colocando como protagonistas de nossa própria história, pois temos muito a ensinar e a aprender.

\section{Referências}

ARROYO, Miguel G. Currículo, território em disputa. Petrópolis, RJ: Vozes, 2011.

BONIN, Iara Tatiana. Educação escolar indígena e docência: princípios e normas na legislação em vigor. In: BERGAMAMASCH, Maria Aparecida; ZEN, Maria Isabel Habckost Dalla; XAVIER, Maria Luísa Merino de Freitas (org). Povos Indígenas e educação. 2. ed. Porto Alegre: Mediação, 2012. 200 p.

CANDAU, Vera Maria Ferrão; RUSSO, Kelly. Interculturalidade e educação na América Latina: uma construção plural, original e complexa. Rev. Diálogo Educ., Curitiba, v. 10, n. 29, p. 151-169, jan. /abr. 2010.

CIR. Plano de Gestão Territorial e ambiental, Terra Indígena Serra da Moça. Conselho Indígena de Roraima, 2017.

D’ ANGELIS, Wilmar da Rocha. Aprisionando Sonhos. A Educação Escolar Indígena no Brasil. Campinas: Curt Nimuendajú, 2012.

FARAGE, Nádia. As flores da fala: práticas retóricas entre os Wapixana. Tese (Doutorado em estudos comparados em leitura de língua Portuguesa, Departamento de Letras Clássicas e Vernáculas) - Faculdade de Filosofia, Letras e Ciências Humanas, Universidade de São Paulo, São Paulo, 1997. 
FERREIRA, Mariana Kawall Leal. A educação escolar indígena: um diagnóstico crítico da situação no Brasil. In: SILVA, Aracy Lopes da; FERREIRA, Mariana Kawall Leal (org). Antropologia, História e Educação: a questão indígena e a escola. São Paulo: Global, 2001.

FREIRE, Paulo. Pedagogia da autonomia: saberes necessários à prática educativa. São Paulo, Paz e Terra, 1996.

GASCHÉ, Jorge. De falar sobre educação intercultural a fazer- la. Mundo amazônico 1: 111134. 2010. Disponível em: https://revistas.unal.edu.co/index.php/imanimundo/article/view/9414. Acesso em: 30 ago. 2019.

LUCIANO, Gersem dos Santos. Educação para manejo e domesticação do mundo: entre a escola ideal e a escola real Os dilemas da educação escolar indígena no Alto Rio Negro. Tese (Doutorado em Antropologia Social) - Universidade de Brasília, Brasília, 2011.

MAIA, Delta Maria de Souza. Os Wapichana da Serra da Moça: entre o uso e desuso das praticas cotidianas (1930/ 1990). Boa Vista: Editora da UFRR, 2014.

NASCIMENTO, Raimundo Nonato Ferreira do. Interculturalidade e educação escolar indígena em Roraima: da normatização à prática cotidiana. Tese (Doutorado em Antropologia) - Universidade Federal de Pernambuco, Recife, 2014.

Referencial curricular nacional para as escolas indígenas/Ministério da Educação e do Desporto, Secretaria de Educação Fundamental. Brasília: MEC/SEF, 1998.

REPETTO, Maxim. Diagnóstico da demanda e da oferta de Ensino Médio para os povos indígenas. (Relatório não Publicado). Brasília, SECADI/MEC, 2006.

A educação escolar indígena em Roraima: o processo histórico e as demandas atuais por ensino médio. In: Roraima em FOCO. Pesquisas e apontamentos recentes. Organizado por Rafael da Silva Oliveira. Boa Vista: Editora UFRR, 2008a, p. 27-51).

UFRR, 2008b.

[et. al]. Propostas educativas em cidadania intercultural. Boa Vista: Editora da

SANCHOTENE, Mônica Urroz; NETO, Vicente Molina. Hábito profissional, currículo oculto e cultura docente: perspectivas para análise da prática pedagógica dos professores de educação física. Revista Pensar Prática Escolar, v. 9, n. 2, 2006.

SANTOS, Mávera Teixeira dos. Educação escolar indígena: uma reflexão a partir do método indutivo intercultural em comunidades indígenas de Roraima. Dissertação (Mestrado em Sociedade e Fronteira) - Universidade Federal de Roraima, Boa Vista, 2019.

SILVA, Rosa Helena Dias da. A autonomia como valor e articulação de possibilidades: O movimento dos professores indígenas do Amazonas, de Roraima e do Acre e a construção de uma política de educação escolar indígena. Cadernos Cedes, ano XIX, n. 49, dez./1999. Disponível em: https://www.scielo.br/pdf/ccedes/v19n49/a06v1949.pdf. Acesso em: 29 jun. 2020. 
SILVA, Tomaz Tadeu da. O currículo como fetiche: a poética e a política do texto curricular. $2^{\mathrm{a}}$ reimp. Belo Horizonte: Autêntica, 2003.

VOLTOLINI, Luiza. Conhecimentos matemáticos: um contexto em transição na comunidade indígena Serra da Moça. Dissertação (Mestrado em Ensino de Ciências e Matemática) - Universidade Luterana do Brasil, Canoas, 2011.

Submetido em 14 de julho de 2020.

Aceito em 13 de outubro de 2020.

Publicado em 01 de dezembro de 2020. 